\title{
Website Design Quality and Form Input Validation: An Empirical Study on Irish Corporate Websites
}

\author{
Mary Levis ${ }^{1}$, Markus Helfert ${ }^{1}$ and Malcolm Brady ${ }^{1}$ \\ ${ }^{1}$ Dublin City University
}

\begin{abstract}
The information maintained about products, services and customers is a most valuable organisational asset. Therefore, it is important for successful electronic business to have high quality websites. A website must however, do more than just look attractive it must be usable and present useful, usable information. Usability essentially means that the website is intuitive and allows visitors to find what they are looking for quickly and without effort. This means careful consideration of the structure of information and navigational design. According to the Open Web Applications Security Project, invalidated input is one of the top ten critical web-application security vulnerabilities. We empirically tested 21 Irish corporate websites. The findings suggested that one of the biggest problems is that many failed to use mechanisms to validate even the basic user data input at the source of collection which could potentially result in a database full of useless information.
\end{abstract}

Keywords: Website Design Quality, Form Input Validation, Information Quality, Data Quality

\section{Introduction}

The World Wide Web (WWW) is the largest available distributed dynamic repository of information, and has undergone massive and rapid growth since its inception. There are over 2,060,000 users in Ireland alone. Over the last seven years (2000 - 2007), Internet usage in Ireland has grown by $162.8 \%$; in United Kingdom by $144.2 \%$; in Europe by $221.5 \%$ and Worldwide by $244.7 \%$ [18].

Based on these facts, the Internet has assumed a central role in many aspects of our lives and therefore creates a greater need for businesses to design better websites in order to stay competitive and increase revenue. Interactivity is essential to engage visitors and lead them to the desired action and customers are more likely to return to a website that has useful interactivity.

The website's homepage should be a marketing tool designed as a 'billboard' for the organization. The design is critical in capturing the viewer's attention and interest [25] and should represent the company in a meaningful and positive light. Therefore, there are many web design concerns for commercial organizations when designing their website.

The most basic are as follows: content that should be included, selecting relevant and essential information, designing a secure, usable, user friendly web interface that is relatively easy to navigate, and ensuring the site is easy to find using any of the major search engines. In the drive to make the website look appealing from a visual perspective other factors are often ignored, such as validation and security, which leads to poor user experience and data quality problems.

Data in the real world is constantly changing therefore feedback is necessary in order to ensure that quality is maintained. Data is deemed of high quality if it 'correctly represents the real-world construct to which it refers so that products or decisions can be made' [30]. One can probably find as many definitions for quality on the web as there are papers on quality. There are however, a number of theoretical frameworks for understanding data quality.

Redman [33] and Orr [27] have presented cybernetic models of information quality. The cybernetic view considers organizations as made up of closely interacting feedback systems that link quality of information to how it is used, in a feedback cycle where the actions of each system is continuously modified by the actions, changes and outputs of the others [2,29,36]. Figure 1 shows an information system in the real world context.

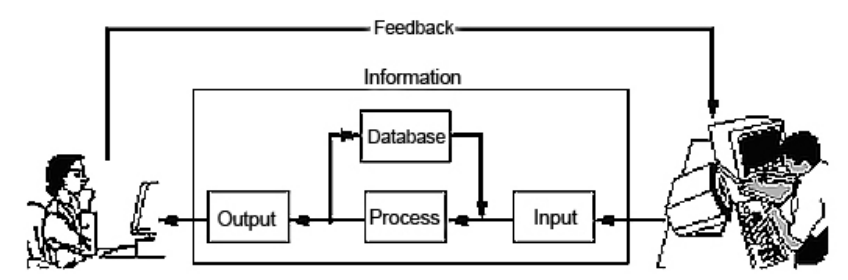

Figure 1: Information system in the realworld context [29] 
Wang and Strong proposed a data quality framework that includes the categories of intrinsic data quality, accessibility data quality, contextual data quality and representational data quality outlined in table 1.

Table1. IQ dimensions [17]

\begin{tabular}{|c|c|}
\hline DQ Category & DQ Dimensions \\
\hline Intrinsic DQ & $\begin{array}{c}\text { Accuracy, Objectivity, } \\
\text { Believability, Reputation }\end{array}$ \\
\hline Accessibility DQ & $\begin{array}{c}\text { Accessibility, } \\
\text { Access Security }\end{array}$ \\
\hline Contextual DQ & $\begin{array}{c}\text { Relevancy, Value Added } \\
\text { Timeliness, Completeness, } \\
\text { Amount of Data }\end{array}$ \\
\hline Representational \\
DQ & $\begin{array}{c}\text { Interpretability, Ease of } \\
\text { understanding, Concise } \\
\text { Representation, } \\
\text { Consistent Representation }\end{array}$ \\
\hline
\end{tabular}

The quality of websites may be linked to such criteria as timeliness, ease of navigation, ease of access and presentation of information. From the customer's perspective usability is the most important quality of a Web application [8].

However, even if all procedures are adhered to, errors can still arise that reduce the quality standard of the online experience. For example, a file may be moved or an image deleted, which results in broken links. The root cause that leads to web application problems is the poor approach to web design.

To remedy this several techniques exist to evaluate the quality of websites for example link checkers, accessibility checkers and code validation. To help improve the quality of a website, aspects such as structure and page layout need to be consistent and coherent. A good website must include safeguards against failure and provide simple, user friendly data entry and validation processes.

From the literature reviewed a universal definition of information quality is difficult to achieve [3, 21, 26, 29, 38, 42]. According to [25] 'Technically, information that meets all the requirements is quality information'. Some accepted definitions of quality from the quality gurus are shown in table 2 .

Table 2. Quality definitions from the quality gurus

\begin{tabular}{|c|c|}
\hline Author & Quality Definitions \\
\hline Deming & Meeting the customers needs \\
\hline Juran & Fitness for use \\
\hline Crosby & Conformance to requirements \\
\hline Ishikawa & Continuous improvement \\
\hline Feigenbaum & Customer satisfaction \\
\hline
\end{tabular}

One definition of quality is 'the totality of characteristics of an entity that bear on its ability to satisfy stated and implied needs' [13, 14]. Two requirements for website evaluation emerge from this definition. 1) general valuation of all the site's characteristics and 2) how well the site meets specific needs.

\subsection{Related Work}

Pernici and Scannapieco [28] discuss a set of data quality dimensions such as expiration, completeness, source reliability, and accuracy to evaluate data quality in web information systems to support correct interpretation of web pages content. Cusimano Com Corp [4] declared that effective web sites must be clear, informative, concise, and graphically appealing.

Tilton [40] recommends that Web designers should present clear information that has a consistent navigation structure. Hylnka and Welsh [12] put forward the argument that the web page is a source of communication and should be analysed within communication theory.

Kelly and Vidgen [16] is concerned with the combination of a quality assessment method, E-Qual, and a lightweight quality assurance method, QA focus and states that website developers need to use standards and best practices to ensure that websites are functional, accessible and interoperable.

There are a number of ways to evaluate the quality of websites, such as competitive analysis, inspection, and online questionnaires. WebQual, developed by Barnes and Vidgen [1] is one approach to the assessment of website quality. WebQual, has 3 main dimensions: usability, information quality, and service interaction quality. According to [1], WebQual is a 'structured and disciplined process that provides a means to identify and carry the voice of the customer through each stage of product and or service development and implementation'.

Usability is concerned with the quality associated with the site design; Information Quality is concerned with the quality of content of the site; Service Interaction quality is concerned with quality provided to the users as they enter into the site. Within these dimensions, WebQual consists of a set of 23 questions regarding the website being assessed and each question contains a rating from 1-7; $1=$ strongly disagree, 7 = strongly agree.

Detailed information about evaluating websites can be found at [24, 34, 35]. Eppler \& Muenzemayer [7] identifies 2 manifestations, 4 quality categories, and 16 quality dimensions. Kahn et al. [17] mapped IQ dimensions to the PSP/IQ model with 2 quality types, 4 quality classifications, and 16 quality dimensions. Zhu \& Gauch [44] outlines 6 quality metrics for information retrieval on the web.

\subsection{What Is a Quality Website?}

Online interactivity is a valuable way of improving the 
quality of business websites and web designers should be aware of how design affects the quality of the website and the image of the organization.

Good websites have a rich and intuitive link structure. A link going to the Customer Service should be named 'Customer Service' and the surfer looking for Customer Service information will know this link goes to the page they want. Therefore, 'click here' should never be used as a link.

Information managers and developers must determine how much information users need [25]. Some users will need much background on a specific topic whilst others may only need a summary or overview. A good web designer will think clearly about how each piece of data links up with the rest of the content on the website and will organize the links accordingly.

Without a clear navigation system, viewers can become disoriented. Hyperlinks are distinguished from normal text within a page by its colour. When the page pointed to by a hyperlink has been 'visited' browsers will inform the users by changing the link's colour [41].

The most vulnerable part of any web application is its forms and the most common activity of web applications is to validate the users' data. According to the Open Web Applications Security Project [27] invalidated input is in the top ten critical web application security vulnerabilities. Input validation is an important part of creating a robust technological system and securing web applications. Because of the fundamental client server nature of the web application, input validation should be done both on the client and the server.

Client side validation is used to provide input data validation at the data collection point before the form is submitted and check that the required fields are filled and conform to certain characteristics such as built in length restriction, numeric limits, email address validity, character data format etc. Incorrect data validation can lead to data corruption.

Table 3. Example validation checks

\begin{tabular}{|c|c|}
\hline Validation check & Description \\
\hline Character set & $\begin{array}{l}\text { Ensure data only contain char- } \\
\text { acters you expect }\end{array}$ \\
\hline Data format & $\begin{array}{l}\text { Ensure structure of data is con- } \\
\text { sistent with what is expected }\end{array}$ \\
\hline Range check & $\begin{array}{c}\text { Data lies within specific range of } \\
\text { values }\end{array}$ \\
\hline Presence check & No missing / empty fields \\
\hline Consistency check & $\begin{array}{l}\text { If title is 'Mr' then gender is } \\
\text { 'Male' }\end{array}$ \\
\hline
\end{tabular}

Input validation should be performed on all incoming data ensuring the information system stores clean, correct and useful data. Examples of invalid data are: text entered into a numeric field, numeric data entered into a text field, or a percentage entered into a currency field. Table 3 provides an example set of checks that could be performed to ensure the incoming data is valid before data is processed or used.

Having contact information available and visible on the website is a marketing plus that potential customers use in order to judge a company's trustworthiness, as it signifies respect for the customer and implies promise of good service.

Feedback mechanisms built into the website are a useful way to get meaningful feedback on the website and service quality from the people who matter most - your customers. After all, one definition of quality is 'meeting or exceeding the customer's expectations'.

One of the most important factors for a website being successful is speed. If the website is unresponsive, with long response times the visitors will not come again. Speed or responsiveness is integral to good website design and organizational success. Web pages should be designed with speed in mind [31]. It is estimated that if a page doesn't load within 5-8 seconds you will lose $1 / 3$ of your visitors [35]. However, many designers believe that with the recent development of broadband, visual aesthetics is now more important as download speed is not such a major concern. Nevertheless, not all users have broadband and this should be taken into consideration.

For the purpose of this study we conducted an empirical study using a data set of twenty one finalists in a recent website quality technology award. The aim of this study was to examine these websites for Technical quality issues from the user's perspective.

Our analysis focused on helping website owners understand the importance of certain website characteristics, quality of information and functionalities. During the analysis we tested functionalities in the website like forms, the navigation process, the relevance of all click through and the page download speed.

The rest of the paper is organized as follows: Section 2 shows our methodology, Section 3 gives a brief summary and Section 4 some conclusions.

\section{Research}

\subsection{Methodology}

We conducted an empirical study on a recent accountancy website quality technology award competition using the full data set of twenty one finalists that included (3) Charity/Not for Profit organizations, (7) Large Quoted Companies, (2) Small Quoted Companies and (9) Statutory and Unquoted Companies. The identity of websites has been concealed due to confidentiality regulations regarding 
their identity.

The aim of this study was to examine these websites for Technical quality issues. This required validating the sites against a series of checkpoints that included: checking that legal and regulatory guidelines were adhered to (e.g. data protection and privacy), that pages conformed to Web-Accessibility standard (e.g. missing 'alt tags'), missing page titles, browser compatibility, user feedback mechanisms, applications were functioning correctly (e.g. online forms are validated for input etc.). It also included evaluation of the main characteristics and structure of the sites for example clear ordering of information, broken links, and ease of navigation. The principle used was based on the same criteria used to evaluate the participants in the 2006 award [10, 32, 39, 43]. The criteria subset used for this study is outlined in table 4.

Table 4. Set of criteria used in our study

\begin{tabular}{|c|}
\hline Validation Criteria \\
\hline Contrast colours support readability \& understanding \\
\hline Professional appearance \\
\hline Do not use 'click here' \\
\hline What you clicked on is title of page jumped to \\
\hline Links back to home page are functional \& relevant \\
\hline Help features available and easy to access \\
\hline Visited links change colour \\
\hline Site map \\
\hline Interactive form validated for input \\
\hline Mailto parameters set correctly? \\
\hline Web address simply a case of adding .com or .ie to \\
\hline Useful search engine provided \\
\hline Site search provided \\
\hline FAQ \\
\hline Data Protection \& Privacy \\
\hline
\end{tabular}

\subsection{Findings and Analysis}

Table 5 shows the number of companies who defaulted and the number of companies who adhered to selected criteria.

Twelve websites did not include a link to their data protection and privacy policy. A help and Frequently Asked Question (FAQ) page is a general requirement for good website design. As far as navigation goes, this page should tell the user how to find products or information and how to get to the sitemap, yet, 10 companies did not have a FAQ link and 11 did not have help features available and easy to access. Seven out of the 21 sites evaluated did not have the mailto parameters set correctly.

Fifteen sites had fully functional and relevant links to other pages and back to the homepage. Thirteen sites promoted contrast colours supporting readability and un- derstanding and 19 had a professional feel and appearance and did not have horizontal scroll bars. Twenty of the total twenty one sites adhered to the criteria of having the title of page jumped also as the label of the link connecting to it. The percentage of sites that adherence to the criteria and the percentage of sites that defaulted on the criteria are shown in figure 2.

Table 5. Criteria for website evaluation

\begin{tabular}{|c|c|c|}
\hline Validation Criteria & $\begin{array}{c}\text { De- } \\
\text { faulted }\end{array}$ & $\begin{array}{c}\text { Ad- } \\
\text { hered }\end{array}$ \\
\hline $\begin{array}{c}\text { Contrast colours support read- } \\
\text { ability and understanding }\end{array}$ & 8 & 13 \\
\hline $\begin{array}{c}\text { Professional appearance } \\
\text { No use of 'click here' links }\end{array}$ & 2 & 12 \\
\hline $\begin{array}{c}\text { What is clicked on is title of } \\
\text { page jumped to }\end{array}$ & 1 & 20 \\
\hline $\begin{array}{c}\text { Links to home page functional } \\
\text { and relevant }\end{array}$ & 6 & 15 \\
\hline $\begin{array}{c}\text { Help features available \& easy to } \\
\text { access }\end{array}$ & 11 & 10 \\
\hline Visited links change colour & 16 & 5 \\
\hline Site map available & 6 & 15 \\
\hline Form validation for input & 17 & 4 \\
\hline Mailto parameters set correctly & 7 & 14 \\
\hline $\begin{array}{c}\text { Web address is a case of add- } \\
\text { ing .com or .ie to company name }\end{array}$ & 4 & 17 \\
\hline Useful search engine provided & 19 & 2 \\
\hline $\begin{array}{c}\text { Site search provided } \\
\text { Frequently Asked Questions }\end{array}$ & 10 & 14 \\
\hline Data Protection and Privacy & 12 & 9 \\
\hline
\end{tabular}

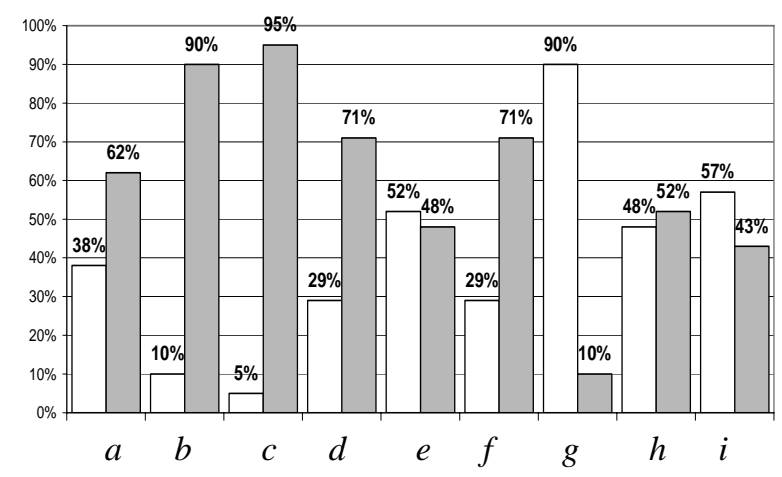

Figure 2. Percentage of sites that defaulted and percentage of sites that adhered to selected criteria (aColours s support readability; b-Professional appearance; c-what clicked on was title of page jumped to; d-Links functional \&relevant; e-Help features available \&easy to access; f-Mailto parameters set correctly. g-Use search engine; h-Frequently asked question page; i-Data protection \&privacy)

Figure 3 depicts the results from the Friendly URLs 
(Uniform Resource Locator). Seventeen (81\%) of the 21 sites tested had good structured semantic URLs, made up of the actual name of the specific company where we could guess the URL by simply adding .com, .org or .ie to the company name. For example a company named 'Jitnu' had a URL http://www.jitnu.ie or http://www.jitnu.com or $h t t p: / / w w w . j i t n u . o r g$ as the web addresses which convey meaning and structure. Only $19 \%$ of the companies examined defaulted on these criteria having a URL for example such as http://www.jitnu.ie/?id=478 instead of http://www.jitnu.ie/services or had a file extension like . php as part of their URL.

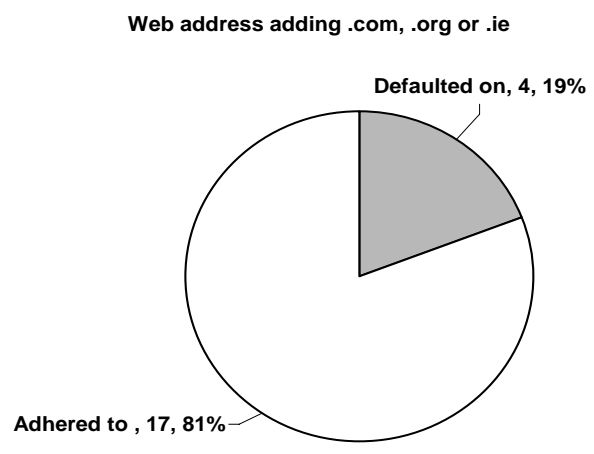

Figure 3. Results of the friendly URL's criteria

Figure 4 shows that 16 (76\%) of the 21 sites examined used the same link colour for visited and unvisited pages and did not support a convention that users expect. Failing on this navigational aid could well increase navigational confusion and introduce usability problems for the user. Good practice is to let viewers see their navigation path history (i.e. pages they have already visited) by displaying links to 'visited pages' in a different colour.

\section{Visited links change colour}

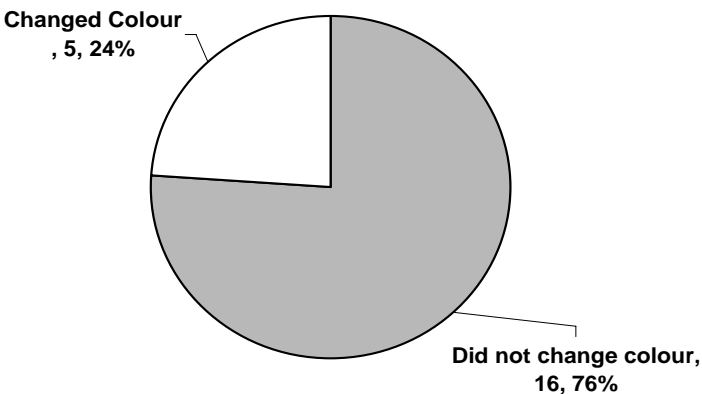

Figure 4. Visited pages changed link colour

Sitemaps are particularly beneficial when users cannot access all areas of a website through the browsing interface. Failure to provide this access option may lose potential viewers. A large website should contain a site map and search option. From analysis of our findings in figure 5, we show that six websites (29\%) did not provide a site map.

Visitors appreciate search capability on sites that deals with several different products or services. In figure 6 we show that although adding a search function on a website helps visitors to quickly find information they need, seven (33\%) of the 21 sites reviewed failed to provide a comprehensive site search or search interface.

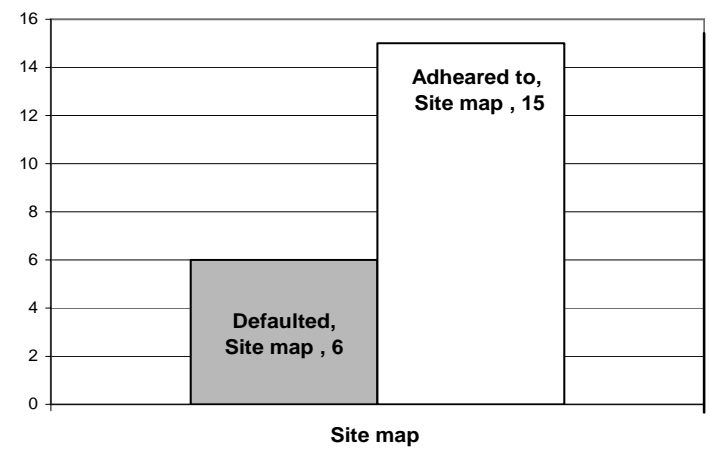

Figure 5. Site map

While creating a good navigation system will be sufficient help for many people, it won't meet the needs of everyone. It appears that these companies fail to realise the importance of providing a search capability, which not only make sites more interactive but also gives visitors more control over their browsing experience.

Provision of search facility

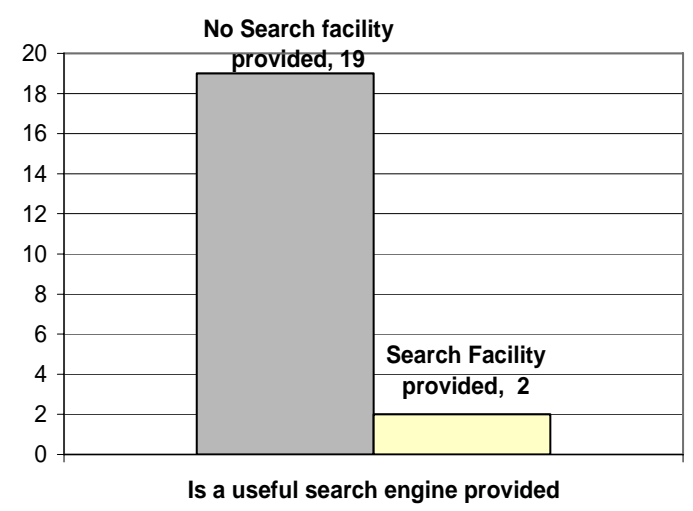

Figure 6. Search facility

Figure 7 shows the results of checking user-entered email addresses for valid input. An email address should contain one and only one (@) and also contain at least one (.). There should be no spaces or extra (@). There must be at least one (.) after the (@) for an email address to be valid. Some websites had implemented some form of email address validation but did so incorrectly. For example they correctly rejected jitnu.eircon.net and jitnu@eircom@net as invalid email addresses, however, they incorrectly accepted 'jitnu.eircom@net', as a valid email address thus allowing an invalid email address to pass to the system as a valid. While they correctly checked for the presence of the (@) and the (.), they did not however check the order in which the (@) and the (.) appeared 
in the inputted email address. From the review of the sites we found that $17(81 \%)$ had no validation process on email addresses while only 4 , (19\%) of the 21 sites reviewed shown in figure 7 had complete validation.

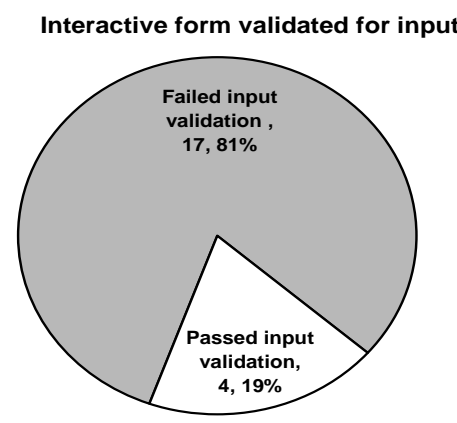

Figure 7. Email validation

Figure 8 shows that 12 (57\%) of the 21 websites were careless about their link text quality by using the 'Click Here', which does not give indication of the content of the linked page, while nine (43\%) used meaningful link text which clearly identified the target of the links.

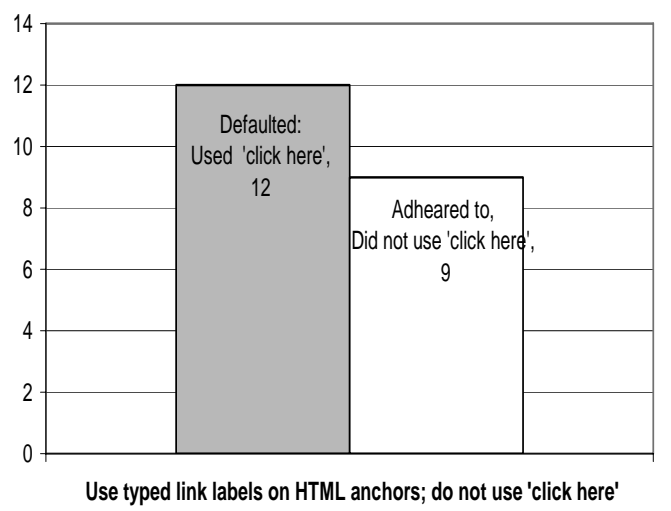

Figure 8. Click here anchors

Figure 9 shows the number of companies that observed and adhered to the quality criteria set out for this review and figure 10 shows the number that defaulted in the above criteria. It can be seen that 19 sites had a professional appearance with no annoying horizontal scroll bars and 20 sites used the page title of the page linked to as an anchor. However only 2 of the 21 sites under review had provided a site search option and 4 sites had complete validation on email addresses.

Figure 11 shows that six out of 21 sites under review did not have their 'mailto' parameter set correctly to facilitate the user with easy feedback option and none of the 21 sites provided an option for the users to view the feedback provided by other users. Providing feedback options greatly enhances the website as many errors go unnoticed until the user draws it to the attention of the organization.

From our analysis we found that all sites had good page load speed between a minimum 0.5 seconds and a maximum of 1.5 seconds and an average load speed of .89 seconds. The average download per Kb was .26 seconds with a minimum speed of .02 seconds and a maximum speed of 3.76 seconds. The minimum site size was .17kb, the maximum site size was $45.68 \mathrm{~kb}$ and the average site size was $20.45 \mathrm{~kb}$.

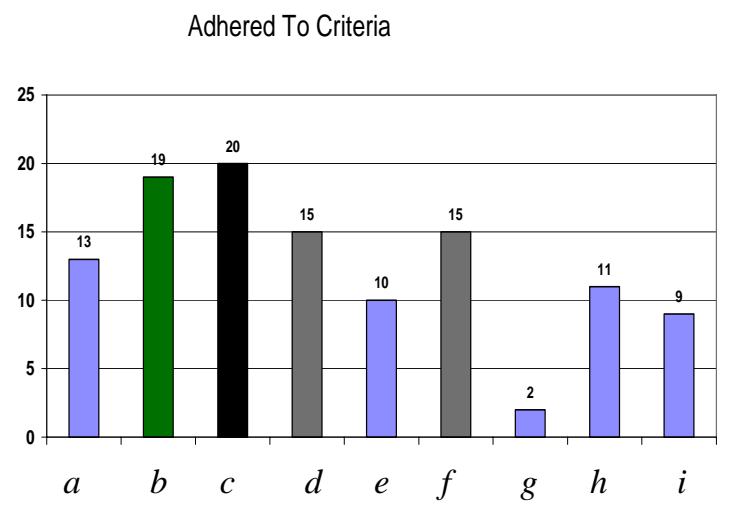

Figure 9. Adhered to selected criteria(a- Colors support readability; b-Professional appearance; c-what clicked on was title of page jumped to; d-Links functional \&relevant; e-Help features available \&easy to access; f-Mailto parameters set correctly. g-Use search engine; h-Frequently asked question page; i-Data protection \&privacy)

Defaulted

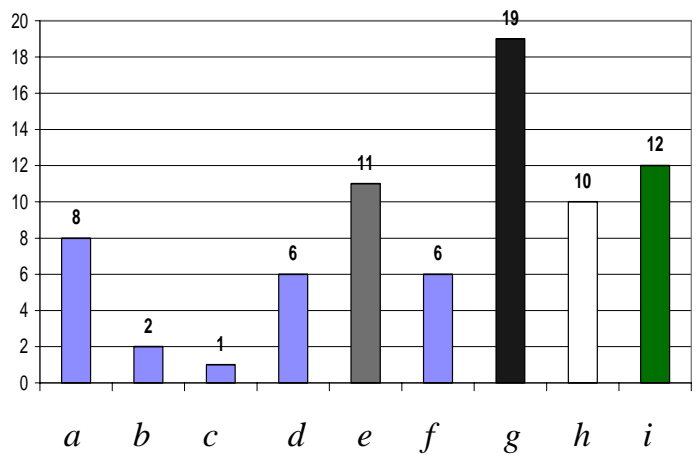

Figure 10. Defaulted on selected criteria(a- Colors support readability; b-Professional appearance;c-what clicked on was title of page jumped to; d-Links functional \&relevant; e-Help features available \&easy to access; f-Mailto parameters set correctly. g-Use search engine; h-Frequently asked question page; i-Data protection \&privacy)

\section{Summary}

The Internet is an interactive channel and successful websites are those that are built on a foundation of interactivity. As the Internet's first real feedback mechanism, forms processing is still the most widely used interactivity on websites. Companies have invested vast amounts of 
money and resources to make their website a strategic part of their business. But what do their customers actually experience when they perform a transaction on their site?

From our study we found that the web applications under investigation were notorious for taking practically any type of input, assuming that it's valid, and processing it further. Not validating input is one of the biggest mistakes that Web-application developers make. This can lead to database corruption. The results from our investigation of the company websites show that one of the biggest problems with online forms on the web is that many corporate companies failed to validate user input to ensure reliability and potentially resulted in a database full of useless information. (See figure 12, figure 13 and figure 14).

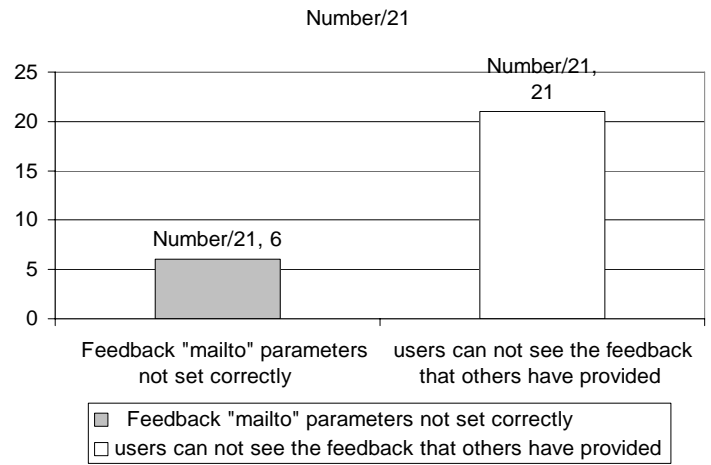

Figure 11. Feedback option and accessibility

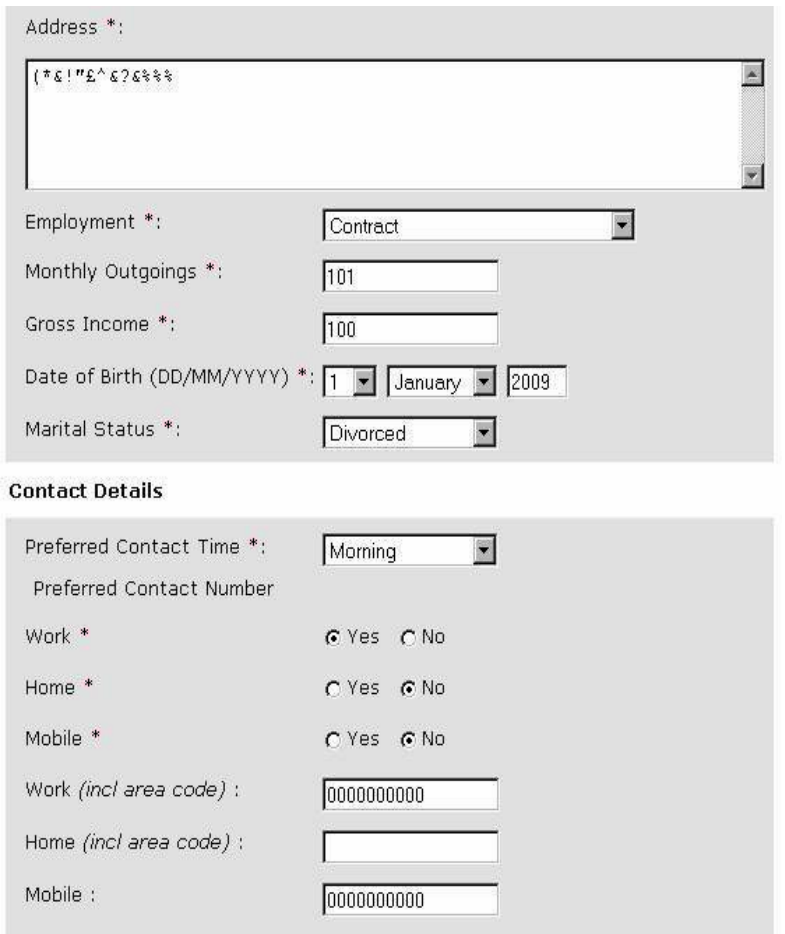

Figure: 12. Example of no date of birth validation on corporate website form

\section{'Call Me'}

Please fill in your details below and one of our Mortgage Advisers will contact you shortly.

Questions marked $*$ are mandatory. Personal Details

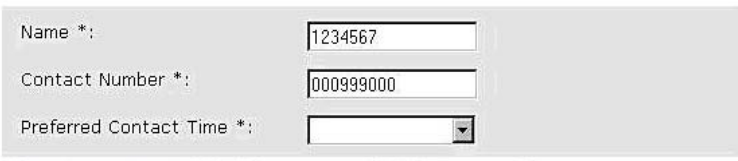

Please ensure your details are correct before proceeding.

Figure 13. Example of trusting the user to enter and validate their own data

\section{Mortgage Application Form}

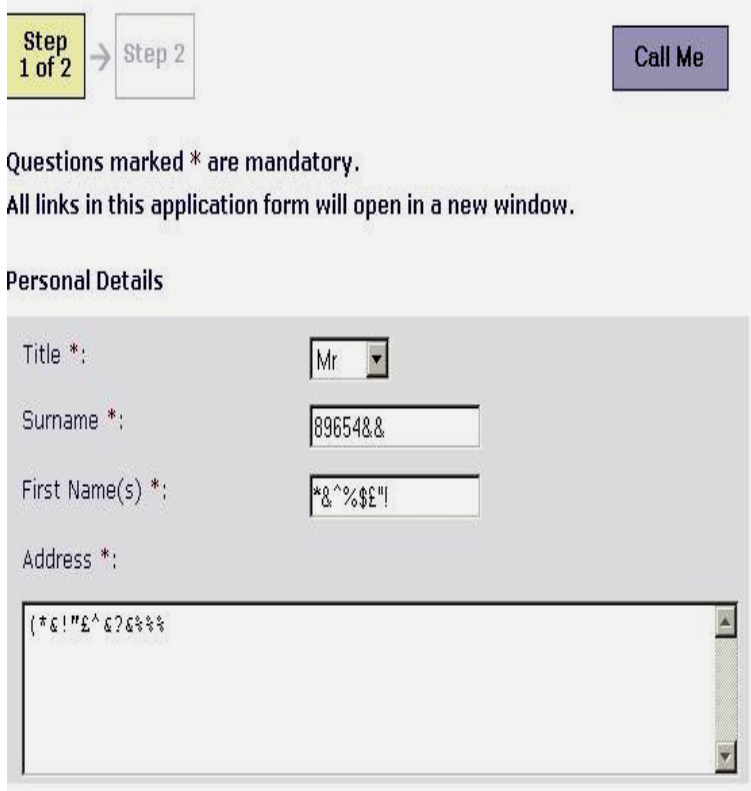

Figure 14. Example of useless information collected in one Irish corporate website

This study highlighted that to date a large number of web applications have not used mechanisms to validate even the very basic data input at the source of collection. Given that the sites under review in this study included large quoted companies, small quoted companies, charities and not for profit, statutory and unquoted organizations and that some had been recognized for excellence in financial reporting; it was surprising to find that $81 \%$ of the sites under examination failed on basic input validation. All $100 \%$ of large quoted companies and $100 \%$ small quoted companies failed in their email input validation while $67 \%$ of charities/not for profit organizations and $67 \%$ of statutory and unquoted organizations under investigation failure to validate emails. No less than $90 \%$ failed to provide a useful search engine but $71 \%$ did provide a 
site map.

Providing a site search function makes the site searchable. The sitemap should include every page on the site, categorized for easier navigation. These are the links that users look for when they cannot find what they are actually looking for on the site. However, 67\% provided a site search facility and $81 \%$ had friendly URL's that were easy to remember and most sites had a good design layout that was consistent throughout. The consistency aspect of quality was closely adhered to by all sites making it easier for the user to navigate.

\section{Conclusions}

Today's Internet user expects to experience personalized interaction with websites. If the company fails to deliver they run the risk of losing a potential customer forever. An important aspect of creating interactive web forms to collect information from users is to be able to check that the information entered is valid, therefore; information submitted through these forms should be extensively validated. Validation could be performed using client script where errors are detected when the form is submitted to the server and if any errors are found the submission of the form to the server is cancelled and all errors displayed to the user. This allows the user to correct their input before re-submitting the form to the server. We can not underestimate the importance of input validation which ensures that the application is robust against all forms of input data obtained from the user.

Although the majority of web vulnerabilities are easy to understand and avoid many web developers are unfortunately not very security-aware. A company database needs to be of reliable quality in order to be usable. A simple check whether a website conforms to the very basic standards could have been done using the W3C HTML validation service, which is free to use.

Web developers need to become aware and trained in Information Quality Management principles, and especially in the information quality dimensions as outlined in Table 2 . The only proven reliable way to deal with bad data is to prevent it from entering the system. Input can be compared against a specific value; ensure that an input field was filled and that the value falls within a certain range. Allowing bad data into the system makes the entire system unreliable and indeed unusable.

Making purchases online is all about confidence; a customer must feel assured that you are a reputable company, and the best way to project that image is through a well designed website. A consumer visiting a website that looks a little dodgy will not feel confident enough to submit their credit card information.

Slow response times and difficult navigation are the most common complaints of Internet users. After waiting past a certain 'attention threshold' users look for a faster site. Of course, exactly where that threshold is depends on many factors. How compelling is the experience? Is there effective feedback? Etc. Our analysis identified these and many other shortcomings that should have been realised and dealt with during the website test phases. Many problems could be eliminated by checking for letters (alphabet entries only); checking for numbers (numeric entries only); checking for a valid range of values ; checking for a valid date input; and checking for valid email addresses. However, it is important to keep in mind that a user could enter a valid e-mail address that does not actually exist. It is therefore, imperative that some sort of activation process needs to be done in order to confirm a valid and correct email address.

\section{Acknowledgements}

This research is funded by Dublin City University Business School.

\section{REFERENCES}

[1] Barnes S. J., and Vidgen R.T., An Integrative Approach to the Assessment of E-Commerce Quality, Journal of Electronic Commerce Research, Vol. 3, No. 3, (2002) pp.114-27.

[2] Beckford J., 2nd edition, Quality, Rutledge Taylor and Frances Group, London and New York (2005).

[3] Bugajski J., Grossman R. L., Tang Zhao., An event based framework for improving information quality that integrates baseline models, casual models and formal models, IQIS 2005 ACM 1-59593-160-0/5/06. (2005).

[4] Cusimano Com Corp., Planning and Designing an Effective Web Site, http://www.cusimano.com/webdesign/articles/effecti v.html .

[5] Clarke R., Internet Privacy Concerns Confirm the Case for Intervention, Communications of the ACM, Vol. 42, No. 2, (1999) pp.60-68.

[6] Cranor L.F., Internet Privacy, Communications of the ACM, Vol. 42, No. 2, (1999), pp.28-31.

[7] Eppler, M \& Muenzenmayer, P, Measuring information quality in the web context: A survey of state of the art instruments and an application methodology. Proceedings of 7th international conference on information quality, (2002), pp.187-196.

[8] Fraternali, P., Tools and Approaches for Developing Data-Intensive Web Applications: A Survey, ACM Computing Surveys, Vol.31, No.3, (1999).

[9] Internet World Statistics http://www.internetworldstats.com.

[10] FFHS Web Award http://www.ffhs.org.uk/awards/web/criteria.php .

[11] Gefen D., E-Commerce: The Role of Familiarity and Trust, Omega, Vol. 28, No. 6, (2000), pp.725-737.

[12] Hlynka D., and Welsh J., What Makes an Effective 
Home Page? A Critical Analysis

http://www.umanitoba.ca/faculties/education/cmns/a ect.html).

[13] ISO 8402, Quality Management Assurance- Vocabulary, Int'l Org. for standardization, (1994) http://www.techstreet.com/iso_resource_center/iso_ 9000_meet.tmpl.

[14] ISO 9241-11, International Organization for Standardization, Geneva, (1998). http://www.idemployee.id.tue.nl/g.w.m.rauterberg/le cturenotes/ISO9241part11.pdf .

[15] Jarvenpaa S.L., N. Tractinsky, and M. Vitale, Consumer Trust in an Internet Store, Information Technology and Management, Vol. 1, No. 1, (2000), pp.45-71.

[16] Kelly B., and Vidgen R., A Quality Framework for Web Site Quality: User Satisfaction and Quality Assurance, WWW 2005, May 10-14, 2005, Chiba, Japan, ACM 1-59593-051-5/05/0005, (2005).

[17] Khan B K ., Strong D.M. \& Wang R.Y., Information Quality benchmarks: Product and service performance, Communications of the ACM, Vol. 45, No 4, (2002), pp.84-192.

[18] Kumar G, Ballou T, Ballou D, P.,Guest editors, Examining data Quality, Communications of the ACM, Vol. 41, No 2, (1998), pp.54-57.

[19] Useit.com: http://www,useit.com/ .

[20] Manchala D.W., E-Commerce Trust Metrics and Models, IEEE Internet Computing, Vol. 4, No. 2, (2000), pp.36-44.

[21] Mandel T., Quality Technical Information: Paving the Way for UsableW3C Web Content Accessibility Guidelines 1.0, http://www.w3.org/tr/wai-webcontent/ .

[22] McKnight, D.H., L.L. Cummings, and N.L. Chervany, Initial Trust Formation in New Organizational Relationships, Academy of Management Review, Vol. 23, (1998), pp.473-490.

[23] McKnight D.H., and N.L. Chervany, An Integrative Approach to the Assessment of E-Commerce Quality, Journal of Electronic Commerce Research, Vol. 3, No. 3, (2002), pp.114-127.

[24] Web standard schecklist. http://www.maxdesign.com.au/presentation/checklist .htm.

[25] Olson J.E., Data Quality: The Accuracy dimension, Morgan Kaufmann, ISBN 1558608915, (2003).

[26] Open Web Application Security Project, http://umn.dl.sourceforge.net/sourceforge/owasp/O WASPTopTen2004.pdf.

[27] Orr K., Data Quality and Systems, Communications of the ACM, Vol. 41, No 2, (1998), pp.66-71.

[28] Pernici B., and Scannapieco M., Data Quality in
Web Information Systems, (2002) 397-413.

[29] Pike R.J., Barnes R., TQM in Action: A practical approach to continuous performance improvement, Springer, ISBN 0412715309 (1996).

[30] Mandel T., Print and Web Interface Design, ACM Journal of Computer Documentation, Vol. 26, No. 3. ISSN: 1527-6805, (2002).

[31] Poll R., and te Boekhorst, P., Measuring quality performance measurement in libraries, 2nd revised., Saur, Munchen, IFLA publications Durban, 127, (2007) http://www.ifla.org/iv/ifla73/index.htm.

[32] Quality Criteria for Website Excellence World Best Website Awards http://www.worldbestwebsites.com/criteria.htm.

[33] Redmond T.C., Improve Data Quality for Competitive Advantage, Sloan Management Review, Vol. 36, No 2, (1995), pp.99-107.

[34] Schulz U., Web usability, http://www.bui.fh-hamburg.de/pers/ursula.schulz/we busability/webusability.html,

[35] Selfso http://www.selfseo.com/website_speed_test.php.

[36] Strong D. M., Lee Y. W., Wang R,Y., Data Quality in Context Communications of the ACM, Vol. 40, No 5, , (1997), pp.103-109.

[37] Stylianou A.C., Kumar R.L., An integrative framework for IS Quality management, Communications of the ACM, Vol. 43, No 9, (2000), pp.99-104.

[38] Tauscher L., Greenberg S., How people revisit web pages: Empirical findings and implication for the design of history systems, International Journal of Human-Computer Studies, Vol. 47, (1997), pp.97-137.

[39] McClainT, http://www.e-bzzz.com/web_design.htm.

[40] Tilton J. E., Composing Good HTML, http://www.cs.cmu.edu/ tilt/cgh/.

[41] Wang R.Y., and Strong D.M. Beyond accuracy: what data quality means to data consumers, Journal of Management Information Systems Vol. 12, No 4, (1996), pp.5-34.

[42] Wang R.Y., A product perspective on Total Data Quality Management, Communications of the ACM, Vol.41, No.2, (1998), pp.58-65.

[43] Web standards http://www.webstandardsawards.com/criteria/\#Crite ria .

[44] Zhu X., and Gauch S., Incorporating quality metrics in centralized distributed information retrieval on the World Wide Web. Proceedings of the 23rd annual international ACM SIGIR conference on Research and development in information retrieval, Athens, Greece. (2000), pp.288-295. 


\section{AUTHORS’ BIOGRAPHIES}

Mary Levis joined Dublin City University Business School as a full time, Ph.D Research Scholar in the field of Information Management, in November 2006. Mary’s work is co-supervised by Dr. Malcolm Brady, Dublin City University Business School, and Dr. Markus Helfert, Dublin City University (School of Computing). Her studies are funded for three years by a scholarship from Dublin City University Business School. She holds a B.Sc degree in Computer Applications (Info Sys) from Dublin City University (School of Computing). Mary has presented her work at many International conferences. Mary is a member of the Irish Computer Society (ICS), British Computer Society (BCS), the International Association of Information Data Quality (IAIDQ), Engineers Ireland (EI) and United Kingdom Academy for Information Systems (UKAIS) Institute for the Management of Information Systems. Mary has been invited by the International Conference on Enterprise Information Systems (ICEIS) to be session chair of an ICEIS-2008 session(s), in Barcelona, Spain. Email: Mary.levis2@mail.dcu.ie

Dr. Malcolm Brady has lectured in management at Dublin City University Business School since 1996. Prior to joining DCU he worked for many years as an IT consultant in the financial services and utility industries and before that as a civil engineer in the design and construction of gas, water, and sewerage systems. He teaches courses in strategic management, project management, and business process innovation. His research interests are in game theory, duopoly, advertising, differentiation and competitive advantage. He graduated from University College Dublin with a Bachelors degree in Civil Engineering and a Masters degree in Management Science; he holds a Diplôme d'Ingénieur from Ecole National Supérieur du Pétrole et des Moteurs, a French Grande Ecole; he obtained an MBA from Dublin City University. He recently completed a PhD from the Department of Economics at Lancaster University. Email: malcolm.brady@dcu.ie

Dr. Markus Helfert is a lecturer in Information Systems at Dublin City University, Ireland and programme chair of the European M.Sc. in Business Informatics at Dublin City University. His research interests include Information Quality, Data Warehousing, Information System Architectures, Supply Chain Management and Business Informatics education. His current research in information quality builds on his PhD research in data quality management in data warehouse systems. He holds a Doctor in business administration from the University of St. Gallen (Switzerland), a Master-Degree in business informatics from the University Mannheim (Germany) and a Bachelor of Science from Napier University, Edinburgh (UK-Scotland). He has authored academic articles and book contributions and has presented his work at international conferences. Email: markus.helfert@dcu.ie 